\title{
CENÁRIOS DA LIBERDADE DE IMPRENSA E OPINIÃO PÚBLICA EM HEGEL *
}

\author{
Agemir Bavaresco ** \\ abavaresco@pucrs.br \\ Paulo Roberto Konzen ${ }^{* * *}$ \\ prkonzen@yahoo.com.br
}

RESUMO Constroem-se, atualmente, os novos cenários para a comunicação tendo, de um lado, as grandes corporações de mídia televisiva, radiofônica, impressa e on-line $e$, de outro, o papel da imprensa independentel alternativa, entendida como não vinculada a uma empresa privada, pública ou estatal, ou algum grupo econômico. Configura-se, aos poucos, a constituição da oposição entre a mídia tradicional e a imprensa independente/alternativa, tendo como suporte material as novas tecnologias da informação. Como a nova tecnologia da informação associada aos novos cenários da liberdade da imprensa e do fenômeno da contradição da opinião pública na era da internet pode realizar a mediação da opinião numa sociedade globalizada? Ou ainda, partindo do pressuposto da liberdade de imprensa, como garantir que a sociedade resolva a contradição da opinião pública? O fenômeno da opinião pública é contraditório, porque contém em si, ao mesmo tempo, a universalidade dos princípios constitucionais, do Direito e da Ética, junto com a particularidade dos direitos e interesses dos cidadãos. Ora, esta contradição encontra a sua solução através da mediação da liberdade da

* Artigo recebido em 16 set. 2008 e aprovado em 18 dez. 2008.

** Doutor pela Universidade de Paris 1, professor de Filosofia da PUCRS. É autor de Teoria hegeliana da opinião pública, entre outros.

*** Doutorando pela UFRGS. É autor de O conceito de Estado e o de liberdade de imprensa na filosofia do direito de G. W. F. Hegel, entre outros.

KRITERION, Belo Horizonte, no 119, Jun./2009, p. 63-92. 
própria imprensa dentro de um quadro de legalidade democrática. Esta é a força da contradição: efetivar a mediação da tensão dialética entre os polos opostos do universal e do singular na liberdade de imprensa, garantindo o direito de todo cidadão expressar publicamente a sua opinião. Esta é teoria da opinião pública hegeliana: a liberdade de imprensa e o parlamento, enquanto espaço político, são esferas privilegiadas da mediação do fenômeno contraditório da opinião pública.

Palavras-chave Liberdade de imprensa; Opinião pública; Imprensa; Jornalistas cidadãos.

ABSTRACT Nowadays, new settings for communication are being built, having, at one side, great corporations of television, radio, press and on line media, and, at the other side, the role of the independent/alternative press, understood as not bound to a private, public or state enterprise, or any economic group. It sets up, gradually the constitution of the opposition between the traditional media and the independent/alternative press, having as material support the new technologies of information. How can the new technology of information associated with new settings of press freedom and the phenomenon of public opinion contradiction in the internet era accomplish the mediation of the opinion in a globalized society? Or still, starting from the assumption of press freedom, how to ensure that society will solve the contradiction of the public opinion? The phenomenon of public opinion is conflicting because it has in itself, at the same time, the universality of constitutional principles of Law and Ethics, and the peculiarity of the citizens' rights and concerns. This contradiction finds its solution through mediation of press freedom within a frame of democratic legality. This is the power of the contradiction: to make effective the mediation of the dialectic tension between the opposite poles of the universal and the singular in the press freedom, ensuring the right of every citizen to express publicly his opinion. This is Hegel's theory of public opinion: the press freedom and the congress, while political space, are privileged spheres of mediation of the contradictory phenomenon the public opinion.

Keywords Press freedom; Public opinion; Press; Citizens journalists.

Constata-se uma mudança em nível da tecnologia da informação, desencadeando novos cenários na liberdade de imprensa e na formação da 
opinião pública. Em que medida a nova tecnologia da informação associada ao papel da imprensa incide na formação da opinião pública? Como esses novos cenários da comunicação, na era da internet, relacionam-se com o fenômeno da opinião pública? Ou ainda, a impaciência da opinião, regida pela rapidez instantânea dos fluxos on-line, pode suportar a paciência da mediação da opinião numa sociedade globalizada? Apresentam-se, inicialmente, os novos cenários da comunicação, a fim de situar a relevância do problema. Depois, descreve-se o desenvolvimento histórico da imprensa no Ocidente e, especificamente, no Brasil, expondo a institucionalização do direito à liberdade de expressão e a formação da opinião pública, contrapondo-se à censura. Por fim, estuda-se a teoria da opinião pública hegeliana enquanto fenômeno da contradição:

\begin{abstract}
A liberdade formal, subjetiva, [consistindo em] que os singulares como tais tenham e externem o seu próprio ajuizar, opinar sobre e aconselhar os assuntos universais, tem o seu aparecimento nesse conjunto que se chama opinião pública. O universal em si e por si, o substancial e verdadeiro está, nela, vinculado com o seu oposto, o peculiar e o particular do opinar dos muitos; esta existência da opinião pública é, portanto, a contradição de si mesma aí presente, - o conhecer como aparecimento; a essencialidade imediata tanto quanto a inessencialidade o é $\left(F D,{ }^{1} \S 316\right)$.
\end{abstract}

A opinião pública é fator importante da liberdade formal subjetiva dos cidadãos. Os indivíduos têm o direito de formular seu julgamento particular sobre o universal, como expressão de sua liberdade subjetiva. A opinião pública não é a verdade política absoluta, mas ela guardará, sempre, a força da impaciência, para desestabilizar toda fixidez ou passividade histórica dada, pois o que move o mundo é a contradição, ${ }^{2}$ e a opinião pública, ela mesma, é uma contradição, que torna efetiva a paciência do conceito. Neste sentido, trata-se de um conceito consistente para justificar o objeto de nosso artigo.

Constroem-se, atualmente, os novos cenários para a comunicação tendo, de um lado, as grandes corporações de mídia televisiva, radiofônica, impressa e on-line e, de outro, o papel da imprensa independente/alternativa, entendida como não vinculada a uma empresa privada, pública ou estatal, ou algum grupo econômico. Configura-se, aos poucos, a constituição da oposição entre a mídia tradicional e a imprensa independentelalternativa, tendo como suporte material as novas tecnologias da informação. Podem-se destacar três mudanças principais neste novo cenário:

1 HEGEL, G. W. F. Linhas fundamentais da filosofia do direito ou direito natural e ciência do estado em compêndio: Terceira parte: a Eticidade; Terceira seção: o Estado. Tradução de Marcos Lutz Müller. Campinas: IFCH/UNICAMP, 1998. (Textos Didáticos; n. 32). Usaremos a abreviação FD.

2 Cf. HEGEL, G. W. F. Enciclopédia das ciências filosóficas em compêndio (1830): I - A ciência da lógica. Tradução de Paulo Meneses. São Paulo: Loyola, 1995. Adendo 2 ao §119. 
a) Imprensa televisiva, radiofônica, impressa e on-line: No entender de Ivana Bentes Oliveira, ${ }^{3}$ há uma homogeneidade entre os jornais e as linhas editoriais na grande imprensa. Há o modelo do jornalismo tradicional da grande empresa corporativa, que passa a utilizar a tecnologia como a internet ou outras possibilidades eletrônicas. Porém, abre-se um novo cenário pluralista, com o sujeito que passa a ser produtor de mídia, ou seja, passa a produzir informação, análise e interpretação dos fatos. Este fenômeno articula outro ator midiático, que se chama mídia independente ou alternativa. Com essa mudança de contexto tecnológico, e até econômico, com o barateamento dessas tecnologias, a mídia independente passa a ser viável e autossustentável, tendo visibilidade para influir na formação e diversificação da opinião pública, posicionando-se criticamente face à grande empresa jornalística.

b) Internet: blogs, lista de e-mails e sites independentes ou a contradição no discurso: A mídia independente transforma, aos poucos, os veículos de comunicação existentes na internet em meios de forte capacidade para influenciar a opinião pública. Há a produção de um contradiscurso, que surge nos blogs, ${ }^{4}$ nas listas de e-mails, dos sites, da mídia independente, implementando a contradição na opinião pública. Difunde-se uma contrainformação com uma rapidez muito grande, o que seria impossível se não houvesse a internet. Prossegue Ivana B. Oliveira, essa possibilidade veloz de reação gera uma disputa midiática, porque o acesso à diversidade é absolutamente facilitado através de políticas públicas e da democratização cada vez maior da internet, bem como da multiplicação da informação.

c) Mudança do conceito de jornalismo - imprensa e jornalistas cidadãos: Há um conhecimento difuso na sociedade que é muito mais amplo e que a imprensa tradicional, os partidos políticos ou a academia não conseguem captar, afirma Luís Nassif. ${ }^{5} \mathrm{O}$ jornalismo tradicional, normalmente, opera assim: o jornalista faz a entrevista; obtém dez informações; seleciona três, porque não cabem as dez; diz o que é relevante ou não; se ele quiser, tira do contexto, e, assim, está elaborada a matéria. Hoje, há uma mudança do conceito de jornalismo, reitera Nassif, com o advento da internet e dos

3 É doutora em comunicação, pela Universidade Federal do Rio de Janeiro, onde hoje é diretora da Escola de Comunicação. Antes de partir para a vida acadêmica, trabalhou em importantes veículos, como o Jornal do Brasil. Entrevista concedida ao IHU On-Line em 24 mar. 2008, disponível em: <http://www. unisinos.br/ihu/>.

4 No Brasil, $51 \%$ dos internautas residenciais navegam em blogs, indica pesquisa do lbope/NetRatings (Zero Hora, n. 360, 20 ago. 2008. ZH Digital).

5 Cf. Luís Nassif, na revista Caros Amigos. Disponível em: <http://www.unisinos.br/_ihu/25.03.2008> 
blogs, porque há uma desconstrução da atitude onipotente do jornalista. Agora, o jornalista coloca a informação na internet e, ao mesmo tempo, obtém a opinião do leitor. Este interage e contradiz ou tem uma opinião diferente da do jornalista. Então, este muda de opinião, estabelecendo-se um exercício de democracia e civilidade, gerando uma reviravolta no mundo da imprensa. No blog, conclui Nassif: "você tem que ter experiência, bom senso e, quando não conhece direito o tema, coloca lá e pede para o pessoal opinar".

Esta caracterização dos novos cenários para a comunicação não tem por finalidade apontar o futuro dos jornais, diante dos problemas publicitários, os desafios face à internet e as novas tecnologias, etc., pois as novas tecnologias não são, necessariamente, excludentes, mas podem ser complementares. ${ }^{6} \mathrm{O}$ problema é que isto implementa uma nova contradição na formação da opinião pública, tal como esta vinha se determinando até o presente momento. Por isso, apresentaremos, primeiramente, a constituição da liberdade de imprensa e o processo de regulamentação em nível ocidental. Depois, descreveremos a constituição histórica da liberdade de imprensa no Brasil e o contraste entre as correntes que defendem uma Lei de Imprensa e os que advogam a ausência de legislação. Assim, pode-se constatar o papel da imprensa como elemento determinante na formação da opinião pública.

\section{Constituição histórica da liberdade de imprensa}

\subsection{Técnicas de difusão da imprensa e sua função}

O conjunto de realidades designadas mediante o conceito de "comunicação pública" ou "imprensa" inicia com o uso de objetos naturais e artificiais como suporte material de transmissão de mensagens, passa pela fase pictórica ou de representação de objetos e de situações cotidianas, através da pintura rupestre ou de hieróglifos, e continua na fase fonética ou de representação de sons articulados da linguagem oral, a partir da invenção do alfabeto (na Fenícia, cerca de 3000 a.C.). Ou seja, ao longo do tempo, as diversas culturas foram descobrindo novos meios ou suportes materiais para se comunicar, superando os limites do emprego dos sinais de fumaça, do fogo das tochas ou do som

6 Randy Covington, Diretor do Ifra Newsplex, um centro de treinamento que promove a integração multimídia em redações de jornais impressos, defende que o futuro dos jornais impressos depende da capacidade de se associarem ao e-mail, blogs e celular. Cf. Folha de S.Paulo, São Paulo, 20 ago. 2008. Caderno Brasil. 
dos tambores, entre outros, permitindo a conservação no tempo e a circulação no espaço de dados que constituem eventos na história da humanidade. A invenção ou difusão da imprensa, em meados do século $\mathrm{XV}$, junto com avanços científicos e tecnológicos, mais a partir do século XIX, tal como a fotografia (1814), o telégrafo de Morse (1837), o telefone (1877), o cinema (1895), o rádio (1909), a película sonora (1927), as ondas curtas (1930), além da televisão a cores, a frequência modulada, os satélites de telecomunicação, os computadores, a fita magnetofônica e o cassete, o videoteipe ou fita fonoótica, os videocassetes e os videodiscos, os celulares, a rede digital, a fibra óptica, os CDs, os DVDs, os pen-drives, os mp $(3,4,5)$, entre outros meios, acabaram diversificando e sofisticando as possibilidades de comunicação.

A comunicação não é algo que se restringe apenas à transmissão verbal, explícita e intencional de alguma mensagem. Mas o âmbito de comunicação inclui todas as formas por meio das quais as pessoas influenciam, de certo modo, outras pessoas. Tal noção se baseia na premissa de que todas as ações ou eventos têm aspectos comunicativos, assim que são percebidos por alguém. Ou seja, sua percepção influencia o conjunto de informações que o indivíduo possui e, assim, de algum modo, comunica-lhe algo. Ora, as funções básicas, convencionalmente atribuídas aos muitos meios de comunicação ou de imprensa, são quatro: informar, divertir, ensinar e persuadir. A primeira diz mais respeito à difusão de notícias, relatos, comentários, etc., a respeito da realidade, acompanhada, ou não, de interpretações ou de explicações. A segunda função atende à procura de distração, de evasão, de divertimento, etc., por parte do público. A terceira - ensinar — é realizada de modo indireto ou direto, intencional ou não, por meio de material visando a formação do indivíduo ou para ampliar seus conhecimentos, planos, etc. A quarta função visa persuadir o indivíduo, convencê-lo, por exemplo, a adquirir o produto, a votar em certo candidato, a se comportar de acordo com as pretensões do anunciante. Ou seja, tais meios, muitas vezes, foram e ainda são usados para cunhar, intermediar e reforçar o consenso ou o arremedo da opinião pública, através do poder da propaganda, a qual é uma tentativa de influenciar a conduta dos indivíduos, pois, afinal, o escopo do propagandista é o de convencer ou de direcionar a opinião alheia. ${ }^{7}$

$\mathrm{Na}$ verdade, somente no século XIX, a imprensa começa a adquirir, propriamente, as características de meio de comunicação dirigido às massas.

7 Cf. KONZEN, Paulo Roberto. O conceito de Estado e o de liberdade de imprensa na filosofia do direito de G. W. F. Hegel. Dissertação (Mestrado em Filosofia) - Universidade Federal do Rio Grande do Sul, Porto Alegre, 2007. p. 157. 
Com o grande desenvolvimento da tecnologia, desencadeado pela Revolução Industrial, as atividades de editoração perdem o feitio artesanal e adotam as técnicas da industrialização. No contexto da produção em massa, os novos bens, fabricados pela indústria editorial, principalmente, os jornais e as revistas, têm o custo barateado, tornando-se produtos de consumo popular. Depois, em função do grande crescimento do número de habitantes da maior parte dos Estados, também a imprensa precisou adaptar-se, já que sempre mais pessoas recebiam instrução e, com isso, sabiam ler e escrever, e podiam, em consequência, querer adquirir os impressos. Mas o mais importante é que as técnicas industriais transformaram-se radicalmente com o grande desenvolvimento da mecânica e da máquina a vapor, a qual foi adaptada à imprensa. Assim, a imprensa escrita acabou convertendo-se, efetivamente, num autêntico e complexo veículo de comunicação de massas. Tal processo ainda foi intensificado com o surgimento do rádio, do cinema, da televisão, da internet, etc., como consequência do progresso científico, tecnologias que, ao longo dos anos, foram se incorporando na estrutura da sociedade. ${ }^{8}$

\subsection{Institucionalização da liberdade de imprensa}

Antes mesmo da descoberta da tipografia (por Gutemberg, em 1454), sobre quase todos os escritos já pesava rigorosa regulamentação tanto de origem religiosa quanto laica. A tipografia, a princípio, é encorajada e favorecida. Mas, com a sua grande difusão, já no início do século XV, os poderes civis e religiosos procuraram se unir, a fim de frear as supostas intemperanças dos impressores. ${ }^{9}$ Assim, quase naturalmente, a imprensa periódica foi, até o fim do século XVIII, sobretudo na França, submetida a um regime preventivo e arbitrário de censura. Tal regime comportou, ao mesmo tempo, a obrigação de obter o direito, no mais das vezes, acompanhado de monopólios, para a edição e a prévia censura de todas as publicações. Para tanto, não existia regra nenhuma que limitasse o poder discricionário de conceder ou recusar as autorizações. Ora, as profissões de impressor, livreiro-editor ou vendedor, a princípio livres, eram sujeitas à regulamentação corporativa, cada vez mais minuciosa e repressiva, reforçada pela regulamentação estatal.

8 Cf. Idem, p. 159.

9 Dada a multiplicação de tipografias e o seu uso por movimentos de contestação, a Igreja Católica já, em 1479, procurou implantar medidas proibitivas e preventivas, através do Papa Sisto IV. Em 17.11.1487, o Papa Inocêncio VIII, na declaração "Inter Multiplices", acabou proibindo a impressão de livros sem exame ou a censura prévia. E, em 1564, o Papa Pio IV, na "Domini Gregis”, instituiu o Catálogo de livros proibidos, mais conhecido por INDEX. Só em 1965, o Papa Paulo VI, na "Integrae Servande”, decretou a abolição do índice dos livros proibidos. 
Mas, das muitas declarações sobre a liberdade em geral, em especial, sobre a de imprensa, até Hegel (1770-1831), cabe destacar: a) a "Declaração da Independência”, de 04.07.1776, e a "Constituição Federal” dos Estados Unidos da América, de 1789, e as emendas de 1791 [Art. XII: "a liberdade de imprensa é um dos grandes baluartes da liberdade, não podendo ser restringida jamais, a não ser por governos despóticos"]; e b) a "Declaração dos Direitos do Homem e do Cidadão", na França, de 26.08.1789 [Art. XI: "A livre comunicação das idéias e das opiniões é um dos mais preciosos direitos do homem; todo cidadão pode, portanto, falar, escrever, imprimir livremente, respondendo, todavia, pelos abusos desta liberdade nos termos previstos na lei"]. ${ }^{10}$

Além disso, depois de Hegel, na Declaração Universal dos Direitos Humanos, aprovada pela Assembléia Geral da Organização das Nações Unidas (ONU), em 10.12.1948, o artigo XIX também defende que toda pessoa tem direito à liberdade de opinião e expressão; sendo que tal direito inclui a liberdade de, sem interferência, ter opiniões e de procurar, receber e transmitir informações e ideias por quaisquer meios e independentemente de fronteiras. Do mesmo modo, na Convenção Européia de Salvaguarda dos Direitos Humanos e das Liberdades Fundamentais, de 04.11.1950, o artigo X defende que todo ser humano tem direito à liberdade de expressão. Tal direito envolve a liberdade de opinião e a de receber e de comunicar informações e ideias, sem a interferência de autoridades públicas e sem consideração de fronteiras. Tal artigo não proíbe os Estados de submeterem as empresas de comunicação a regime de autorização, tudo porque o exercício da liberdade de expressão, que comporta deveres e responsabilidades, pode ser sujeito a certas formalidades, condições, restrições ou sanções previstas em lei, as quais constituem medidas necessárias, numa sociedade democrática, à segurança nacional, integridade territorial, defesa e manutenção da ordem pública, prevenção de crimes, proteção da saúde e da moral, proteção da reputação ou dos direitos de terceiros, e para impedir a divulgação de informações confidenciais ou garantir a autoridade e imparcialidade do poder judiciário. Ainda cabe destacar que, em 28.11.1978, na 20ª reunião da Conferência Geral da ONU para a Educação, a Ciência e a Cultura, celebrada em Paris, foram declarados os princípios fundamentais relativos à contribuição dos meios de comunicação de massa para o fortalecimento da paz e da compreensão internacional, para a promoção dos direitos humanos e a luta contra o racismo, o apartheid e o incitamento à guerra. São onze artigos, cujo preâmbulo 
relembra que a liberdade de informação é um direito humano fundamental e alicerce de todas as liberdades às quais estão consagradas as Nações Unidas, mas que a liberdade de informação requer, como elemento indispensável, a vontade e a capacidade de usar, e de não abusar, de seus privilégios, já que requer a disciplina básica ou a obrigação moral de pesquisar os fatos e difundir os seus dados, sem intenção maliciosa.

Em síntese, trata-se da luta contra a difusão de notícias falsas ou deformadas, que poderiam provocar ou estimular ameaças contra o interesse da paz e do bem-estar da sociedade. Muitos de tais elementos já se encontram expressos por Hegel, o qual já destaca, por exemplo, a necessidade de transmitir, pelos veículos de comunicação, o que, de fato, se passa na realidade e não ter tal informação sonegada por decisão autoritária do governo ou determinação arbitrária do editor do veículo. ${ }^{11}$

\subsection{Liberdade de imprensa no Brasil}

No Brasil, sabemos que a Imprensa Nacional, órgão criado pelo Decreto de 13.05.1808 (ou seja, há mais de 200 anos), assinado por Dom João VI, instituiu aqui os parâmetros da Lei de Imprensa portuguesa. Depois da Independência, o direito positivo brasileiro em matéria de imprensa possui seus dispositivos divididos entre a Constituição e a Lei de Imprensa. Ora, por decreto de 18.06.1822, nossa imprensa ingressou na legislação ordinária. Mas a primeira Lei de Imprensa foi a Carta de Lei de 02.10.1823; seguindose, depois, a de 20.09.1930. A Lei ${ }^{\circ} 4.743$, de 31.10.1923, regulou nossa imprensa até o advento da Lei $\mathrm{n}^{\circ} 2.183$, de 12.11.1953, sem omitir o Decreto $\mathrm{n}^{\circ}$ 24.776, de 15.07.1934, que remanesceu durante a ditadura militar, alterado pelas leis e normas do Departamento de Imprensa e Propaganda (DIP), criado em 1939. A Lei no 4.680, art. 17, de 18.06.1965, regulamentou a profissão do publicitário e agenciador de propaganda. O art. 17, do Decreto ${ }^{\circ} 57.690$, de 01.02.1966, sobre o regulamento para a execução da Lei $n^{0} 4.680$, estabeleceu regras de natureza ética a respeito do que não é permitido e do que constitui o dever na comunicação pública.

Ora, na Constituição Imperial de 1824, a "liberdade de comunicação do pensamento por palavras e escritos e vinculada por meio da imprensa" era tutelada no art. 179, inciso IV: "Todos podem comunicar os seus pensamentos por palavras, escritos e publicá-los pela imprensa, sem dependência de censura, contanto que hajam de responder pelos abusos que cometerem no exercício 
deste direito, nos casos e pela forma que a lei determinar". Na Constituição Republicana de 1891, poucas mudanças: "Em qualquer assunto é livre a manifestação do pensamento pela imprensa, ou pela tribuna, sem dependência de censura, respondendo cada um pelos abusos que cometer, nos casos e pela forma que a lei determinar. Não é permitido o anonimato". A Constituição de 1934, de inspiração liberal, rezava em seu artigo 113, item 9: "Em qualquer assunto é livre a manifestação do pensamento, sem dependência de censura, respondendo cada um pelos abusos que cometer, nos casos e pela forma que a lei determinar. Não é permitido o anonimato. É assegurado o direito de resposta. A publicação de livros e periódicos independe de licença do poder público. Não será, porém, tolerada propaganda de guerra ou de processos violentos para subverter a ordem pública ou social”. A Constituição de 1937, no seu artigo 122, item 15, dispunha: "Todo cidadão tem o direito de manifestar o seu pensamento, oralmente, por escrito, impresso ou por imagens, mediante as condições e os limites prescritos em lei”. Porém, em seguida, limita essa disposição liberal ao afirmar: "A lei pode prescrever: a) com o fim de garantir a paz, a ordem e a segurança pública, a censura prévia da imprensa, do teatro, do cinematógrafo, da radiodifusão, facultando à autoridade competente proibir a circulação, difusão ou a representação". Na Carta de 1946, no seu artigo 41, parágrafo 5: "É livre a manifestação de pensamento, sem que dependa de censura, salvo quanto a espetáculos e diversões públicas, respondendo cada um, nos casos e na forma que a lei preceituar, pelos abusos que cometer. Não é permitido o anonimato. É assegurado o direito de resposta. A publicação de livros e periódicos não dependerá de licença do poder público. Não será, porém, tolerada, propaganda de guerra, de processos violentos para subverter a ordem política e social, ou de preconceitos de raça ou de classe". A Constituição de 1967, já sob o regime militar de 1964, afirmava, no seu artigo 150, parágrafo 8: 'É livre a manifestação de pensamento, de convicção política ou filosófica e a prestação de informação sem sujeição à censura, salvo quanto a espetáculos e diversões públicas, respondendo cada um nos termos da lei, pelos abusos que cometer. É assegurado o direito de resposta. A publicação de livros, jornais e periódicos independe de licença da autoridade. Não será, porém, tolerada a propaganda de guerra, de subversão da ordem ou de preconceitos de raça ou de classe". Esta Constituição sofreu emendas sucessivas, a partir da Emenda ${ }^{\circ}{ }^{1}$, de 1969, que trouxeram pequenas modificações no estilo. A matéria da censura e da liberdade de opinião ficou assim regulada pelo artigo 153, parágrafo 8, com a seguinte redação: "É livre a manifestação de pensamento, de convicção política ou filosófica, bem como a prestação de informação independentemente de censura, salvo quanto a diversões e espetáculos públicos, respondendo cada 
um, nos termos da lei, pelos abusos que cometer. É assegurado o direito de resposta. A publicação de livros, jornais e periódicos não depende de licença de autoridade. Não serão, porém, toleradas a propaganda de guerra, de subversão da ordem ou de preconceitos de religião, de raça ou de classe, e as publicações e exteriorizações contrárias à moral e aos bons costumes". ${ }^{12}$

A Constituição Federal vigente, promulgada em 05.10.1988, também trata do direito à comunicação. Já aparece, no seu título II, capítulo I, artigo $5^{\circ}$, o que se lê: "IV - é livre a manifestação do pensamento, sendo vedado o anonimato; $\mathrm{V}$ - é assegurado o direito de resposta, proporcional ao agravo, além da indenização por dano material, moral ou à imagem; (...) IX - é livre a expressão da atividade intelectual, artística, científica e de comunicação, independentemente de censura ou licença; X - são invioláveis a intimidade, a vida privada, a honra e a imagem das pessoas, assegurado o direito à indenização pelo dano material ou moral decorrente de sua violação; (...) XIV - é assegurado a todos o acesso à informação e resguardado o sigilo da fonte, quando necessário ao exercício profissional". Depois, ainda é importante o capítulo IV, o da comunicação social, em que, do artigo 220 ao 224, é garantido o direito à liberdade de expressão, à liberdade de imprensa, proibindo a censura de natureza política, ideológica e artística, exceto por ocasião do Estado de sítio. Trata-se de grandes avanços no que tange à liberdade de imprensa e ao direito de informar e ser informado.

Além disso, o Governo Federal, por meio da Lei nº 9.883, de 07.12.1999, instituiu o Sistema Brasileiro de Inteligência e, deste modo, criou a Agência Brasileira de Inteligência (ABIN), fundamentado nas ideias de preservação da soberania nacional, de defesa do Estado democrático de direito e de defesa da dignidade da pessoa humana. Sua atividade tem por finalidade a obtenção, análise e disseminação de conhecimentos, dentro e fora do território nacional, sobre fatos e situações de imediata ou potencial influência sobre o processo decisório e a ação governamental e sobre a salvaguarda e a segurança da sociedade e do Estado. Seu artigo $3^{\circ}$ impõe que o desenvolvimento das suas atividades dar-se-á com irrestrita observância dos direitos e garantias individuais, fidelidade às instituições e aos princípios éticos que regem os interesses e a segurança do Estado. Por sua vez, a Lei $\mathrm{n}^{\circ} 10.406$, de 10.01.2002, que deu origem ao novo Código Civil Brasileiro, nos artigos 186 e 187, conceitua ato ilícito como sendo uma ação ou omissão voluntária, negligente ou imprudente, que viola direito e causa dano a outrem, ainda

12 Cf. GOMES, Pedro Gilberto. Comunicação social: filosofia, ética, política. São Leopoldo: Unisinos, 1997. p. 96-98. 
que exclusivamente moral. Assim, comete ato ilícito o titular de um direito que, ao exercê-lo, excede manifestamente os limites impostos pelo seu fim econômico ou social, pela boa-fé ou pelos bons costumes. Além disso, cabe destacar que a Secretaria de Estado da Comunicação do Governo Federal, em 06.06.2002, expediu a Instrução Normativa $\mathrm{n}^{0} 28$, instituindo e definindo a "publicidade de utilidade pública" como a que tem como objetivo informar, orientar, avisar, prevenir ou alertar a população ou segmento da população para adotar comportamentos que lhe tragam benefícios sociais reais, visando melhorar sua qualidade de vida.

Trata-se de conjunto complexo e interligado de questões que, muitas vezes, podem entrar em conflito. Sobre isso, são muitos os aspectos que poderiam e, de certa forma, deveriam ser explicitados; por exemplo, sobre os crimes que podem ser cometidos através de órgãos de comunicação pública, a saber: a calúnia e a difamação, a ofensa à memória de pessoa falecida, à pessoa coletiva ou instituição, entre outros atos tidos como abusos da liberdade de imprensa, todos envolvendo a colisão entre o direito subjetivo e o objetivo, público e privado, pessoal e patrimonial, social e individual, setorial e profissional, civil e político; sem falar da relação entre os segredos de justiça (e os domínios particular, privado e íntimo da vida das pessoas) e a liberdade de informação, dos direitos autorais, entre outros tantos, inclusive dos crimes no âmbito da informática. Ora, uns apregoam o valor absoluto dos direitos da personalidade, fixando a inviolabilidade dos referidos direitos, face ao direito de informação. Outros fixam o direito de informação como preferencial aos demais direitos, na medida em que ele constitui um verdadeiro alicerce da instituição da opinião pública, o que faria com que prevalecesse aos demais direitos, nas situações de conflito. Mas uma terceira corrente defende a ponderação entre o direito de informação e os direitos de personalidade, verificando se a restrição resultante dessa ponderação está, ou não, justificada constitucionalmente. Porém, o que transparece é que, a princípio, não se pode falar em proteção aos direitos da personalidade, da garantia da intimidade e, ao mesmo tempo, em liberdade sem limites de informação. Sobre isso, vale ressaltar o que afirma Aníbal Alves:

Daqui ressalta a vocação mediadora da imprensa entre o caos dos fatos e o mundo inteligível próprio dos humanos. Simultaneamente se realça o seu papel na formação do pensamento e atitudes dos indivíduos e conseqüente influência na opinião pública, o que levanta o poder da imprensa e da sua ligação com os diferentes poderes que tendem a usá-la em seu proveito. Importa reconhecer, por um lado, que a relação da imprensa com o poder político e econômico é inevitável e que a forma de lhe salvaguardar a independência reside no fato de aquelas relações serem claramente definidas e conhecidas; por outro lado, a idéia da imprensa como quarto poder só 
é aceitável enquanto tal poder corresponder ao poder do seu público, sem o que a "imprensa que a liberdade criou se torna senhora da liberdade". Por isso mesmo, e qualquer que seja o estatuto jurídico e formal da imprensa, o seu funcionamento deveria tender para se tornar a efetiva expressão do público para o público. Assim realizaria a imprensa a sua função de mediação social, e tanto mais quanto maior for a capacidade crítica de informadores e informados. ${ }^{13}$

O debate sobre a liberdade de imprensa no Brasil coloca-se, atualmente, grosso modo, na oposição entre a corrente que defende a necessidade de uma nova Lei de Imprensa, a qual substitua a anterior do período militar, e aquela que propõe nenhuma legislação específica, ou seja, um laissez-faire na atividade da imprensa. Vejamos como se articulam estas posições.

\subsection{Lei de Imprensa ou ausência de Legislação}

O ministro do Supremo Tribunal Federal (STF), Ayres Britto, determinou, em 02.2008, a suspensão, em caráter liminar, de 20 artigos da Lei de Imprensa, de 1967, adotada durante o regime militar, que impunha restrições à atividade jornalística.

AAssociação Nacional de Jornais (ANJ) entende que o STF poderá decidir, ainda neste ano, pela manutenção da decisão de Ayres Britto, pois para esta "a lei em vigor é um símbolo de um Brasil que deve ficar no passado". A ANJ, reunida no $7^{\circ}$ Congresso Brasileiro de Jornais (São Paulo, 18-19.08.2008), propôs que a atividade de imprensa, no Brasil, permaneça livre de controles externos, tendo em vista que "a todo momento surgem projetos do Legislativo ou do Executivo que podem conter aspectos perigosamente autoritários". Mas diferente é a posição do Presidente da Câmara, Arlindo Chinaglia, presente ao evento como representante do Congresso. Ele defendeu a necessidade de apresentar projetos relativos a uma nova lei para a atividade de imprensa, uma vez que é "difícil imaginar um setor da sociedade que não seja subordinado ao ordenamento jurídico da própria sociedade". ${ }^{14}$

Há consenso, da parte de advogados, políticos, jornalistas e representantes de veículos de comunicação de que a atual legislação para a imprensa, feita em 1967, no regime militar, está ultrapassada; no entanto, divergem quando se trata de encontrar uma solução. Temos duas posições:

a) Necessidade de uma Lei de Imprensa: Uma corrente sustenta que há necessidade de uma nova lei para regular o trabalho da imprensa. Após a

13 ALVES, A. Imprensa. In: Polis: enciclopédia verbo da sociedade e do Estado. Lisboa: São Paulo: Verbo, 1985. p. 434.

14 Cf. Folha de S.Paulo, 19 ago. 2008. Caderno Brasil. 
suspensão, em caráter provisório, de 20 artigos da Lei de Imprensa, esta corrente defende a necessidade de formular uma legislação moderna e democrática para a imprensa, a fim de evitar o risco de se criar um vácuo jurídico. Neste sentido, tramita, na Câmara dos Deputados, projeto de Lei de Imprensa, tal como foi aprovado pela Comissão de Ciência e Tecnologia, Comunicação e Informática, em 06.12.1995, o qual propõe regulamentar o funcionamento da imprensa no Brasil. ${ }^{15}$

b) Ausência de Legislação sobre a Imprensa: Outra corrente de opinião defende a ausência total de legislação específica para a área, ou seja, a simples extinção da Lei de Imprensa, de 1967, sem que nenhuma legislação seja colocada em seu lugar. Argumenta que toda tentativa de regular a atividade jornalística acaba criando excessivo controle sobre o direito à informação, pilar da democracia.

De fato, este dilema sobre a lei da liberdade de imprensa remete a um grande problema histórico, pois, nas democracias modernas, existe o conflito clássico entre dois valores fundamentais garantidos constitucionalmente:

a) Primeiramente, o direito à informação: "É assegurado a todos o acesso à informação e resguardado o sigilo da fonte, quando necessário ao exercício profissional" (CF/1988, art. $5^{\circ}$, inc. XIV).

b) Depois, os direitos ligados à personalidade: "São invioláveis a intimidade, a vida privada, a honra e a imagem das pessoas, assegurado o direito a indenização pelo dano material decorrente de sua violação" $(\mathrm{CF} / 1988$, art. $5^{\circ}$, inc. X).

Face a tal contradição, as Constituições resolveram o dilema conferindo primazia ao primeiro direito, em nome do interesse público: "A manifestação do pensamento, a criação, a expressão e a informação, sob qualquer forma, processo ou veículo não sofrerão qualquer restrição, observado o disposto nesta Constituição" (CF/1988, art. 220). Acrescenta, neste mesmo artigo, $\S 1^{\circ}$ : "Nenhuma lei conterá dispositivo que possa constituir embaraço à plena liberdade de informação jornalística em qualquer veículo de comunicação social"; e §2o: "É vedada toda e qualquer censura de natureza política, ideológica e artística".

Mas, como contrapartida, criaram-se mecanismos para reparar excessos cometidos no livre exercício da imprensa, através dos Códigos Civil e Penal, 
que avaliam a atividade jornalística, garantindo a honra, a intimidade e a privacidade das pessoas. ${ }^{16}$ Assim, o novo Código Civil, no artigo 20, autoriza a proibição de escritos, exposição e utilização de imagem se eles atingirem a honra, a boa fama e a respeitabilidade de alguém..$^{17}$ Esse artigo, conjugado com o artigo 12, também do Código Civil, institui uma espécie de censura prévia contra imprensa, rádio e televisão, além da indenização que couber. ${ }^{18}$

Constata-se que a liberdade de imprensa tem como pressuposto o desenvolvimento tecnológico dos meios de comunicação, em que a crescente evolução das técnicas de imprensa permite que a humanidade passe, cada vez mais, de meios interpessoais para instrumentos massivos de comunicação. Ora, a conjuntura da opinião pública surge neste movimento de institucionalização da liberdade de imprensa, através das Revoluções americana e francesa, em que as várias Declarações garantem o direito à liberdade de imprensa. Enfim, a Declaração Universal dos Direitos Humanos afirma, em seus artigos, que a liberdade de informação é um direito humano fundamental e alicerce de todas as liberdades. No Brasil, as Constituições, desde a primeira, em 1824, até a última, em 1988, sempre contemplaram o direito à liberdade de imprensa, procurando incorporar a expansão deste direito às democracias ocidentais.

Assim, a constituição histórica da liberdade de imprensa reflete o embate entre liberdade de opinião e censura, em que a opinião pública desenvolve a contradição que encontra na própria imprensa a função mediadora. É isso que veremos, a seguir, na experiência e na filosofia hegeliana sobre a liberdade de imprensa e a opinião pública.

\section{Liberdade de imprensa e opinião pública em Hegel}

Para apreender bem o conceito hegeliano de liberdade de imprensa ou de comunicação pública, cabe examiná-lo diante das circunstâncias em que foi exposto, a fim de evitar as interpretações equivocadas. Ora, por meio da leitura histórica e crítico-filológica, podemos citar e analisar as interpretações existentes acerca da filosofia hegeliana, pois há uma disputa entre o que ele, a princípio, disse e aquilo que dizem que Hegel disse e/ou o que poderia ter dito.

16 Cf. Editorial Folha de S.Paulo, 30 mar. 2008.

17 "Salvo se autorizadas, ou se necessárias à administração da justiça ou à manutenção da ordem pública, a divulgação de escritos, a transmissão da palavra, ou a publicação, a exposição ou a utilização da imagem de uma pessoa poderão ser proibidas, a seu requerimento e sem prejuízo da indenização que couber, se Ihe atingirem a honra, a boa fama ou a respeitabilidade, ou se destinarem a fins comerciais" (Código Civil, art. 20).

18 "Pode-se exigir que cesse a ameaça, ou a lesão, a direito da personalidade, e reclamar perdas e danos, sem prejuízo de outras sanções previstas em lei" (Código Civil, art. 12). 
Ou seja, diante das muitas interpretações sobre a filosofia política de Hegel, que se multiplicam e se entrechocam, ao reconstituir as circunstâncias históricas em que o texto hegeliano da Filosofia do Direito foi editado, aliado à análise dos seus elementos crítico-filológicos, é possível discernir, por exemplo, que, apesar de muitas similaridades, a definição hegeliana do conceito de Estado é distinta da forma estatal vigente na Prússia: simplesmente, tal monarquia não era constitucional e não se encontrava alicerçada sobre o princípio da liberdade, porque vigorava forte censura, procurando prever e controlar tudo, impedindo, assim, a livre iniciativa dos seus membros ou a livre atuação política dos cidadãos, tornando-se, com isso, autoritária. ${ }^{19}$

\subsection{Hegel e a Lei de Imprensa Federal da Convenção de Karlsbad}

Historicamente, trata-se do fato de Hegel ter escrito e publicado a Filosofia do Direito, em 1820, numa época em que a Prússia se encontrava em pleno estado de censura, dada a recente implementação, em 20.09.1819, das resoluções da Convenção de Karlsbad, realizada de 06 a 31.08.1819, produto do acordo entre o então monarca prussiano, Frederico Guilherme III, e o chanceler Metternich. Ou seja, houve todo um clima político de repressão e vigilância, especialmente nos meios universitários e na imprensa, em função da vigência de tais resoluções. Ora, cogita-se que Hegel, nessa época, já tinha pronto para a impressão o texto da Filosofia do Direito. Porém, o que, de fato, sabemos é que o seu Prefácio expõe local e data, a saber: "Berlim, 25 de junho de 1820"; ou seja, apenas nove (09) meses depois do início da vigência das resoluções.

Ora, o objetivo básico das referidas Resoluções de Karlsbad era o de cercear o movimento liberalista nos Estados alemães, onde a agitação revolucionária, localizada sobretudo nos círculos intelectuais e universitários, havia encontrado espaço especialmente nas organizações estudantis, as quais já haviam provocado agitações em vários Estados da Confederação Germânica. Em resumo, foram três resoluções, aprovadas mediante decisão da assembleia ministerial: a [1] Lei Universitária Federal ("Resolução federal provisória sobre as providências a serem tomadas na consideração da Universidade"), a [2] Lei de Imprensa Federal ("Determinação provisória sobre a Liberdade de Imprensa") e, ainda, a [3] Lei de Investigação Federal ("Resolução relativa ao pedido da autoridade central acerca da investigação para descobrir, nos diferentes Estados confederados, intrigas revolucionárias").

19 Cf. KONZEN, Paulo Roberto. O conceito de Estado e o de liberdade de imprensa na filosofia do direito de G. W. F. Hegel. Dissertação (Mestrado em Filosofia) - Universidade Federal do Rio Grande do Sul, Porto Alegre, 2007. Conclusão, p. 191. 
$\mathrm{Na}$ “Lei de Investigação Federal”, destaca-se o art. 2:

A finalidade desta Comissão é a investigação e a verificação em comum, quanto mais escrupulosa e abrangente possível dos atos reais, da procedência e das variadas ramificações contra a existente constituição e interior tranqüilidade, tanto em toda Confederação, quanto em cada um dos Estados confederados, constituídas as revolucionárias intrigas e as demagógicas associações, das quais os mais próximos ou distantes indícios já existem, ou se querer intervir no andar da investigação.

\section{E da "Lei de Imprensa Federal" cabe destacar o $§ 1$ :}

Enquanto a presente resolução permanecer em vigor, não poderá ser impresso nenhum escrito, este na forma de periódico diário ou caderno aparente, igualmente semelhante, não excedendo acima de 20 folhas no prelo, em nenhum Estado confederado alemão sem conhecimento prévio e precedente revisão geral pelo serviço público de imprensa local.

Em resumo, tais resoluções intensificaram a austeridade nas Universidades, limitando a liberdade do pensamento e da ciência, e a censura, restringindo, ainda mais, a liberdade de comunicação pública existente na época. ${ }^{20}$

Diante disso, segundo P. Singer, é mais do que necessário esclarecer se o conceito de Estado de Hegel é ou não meramente uma descrição do Estado prussiano da época em que ele escreveu. Para Singer: "Não, não é. Há grandes similaridades, mas há também diferenças significativas. Mencionarei quatro delas. (...)":

A terceira diferença é que Hegel era, ainda que dentro de limites muito estritos, um defensor da liberdade de expressão. Para os padrões atuais, reconhecidamente, ele não parece ser nada liberal nesta questão, pois excluía dessa liberdade tudo o que viesse a se caracterizar como difamação, abuso ou "caricatura insolente" do governo e de seus ministros. Entretanto, não queremos agora julgá-lo pelos padrões de hoje, e sim comparar suas propostas com o estado de coisas na Prússia na época em que ele estava escrevendo. Ademais, como a Filosofia do Direito apareceu apenas dezoito meses depois da rígida censura imposta pelos decretos de Karlsbad de 1819, Hegel estava certamente lutando por uma liberdade de expressão maior do que a que se permitia no momento. (...) Essas diferenças são suficientes para isentar Hegel da acusação de haver erigido sua filosofia inteiramente para agradar à monarquia prussiana. $^{21}$

Em síntese, Hegel lutou por uma liberdade de expressão maior do que a que se permitia na época da redação e da publicação da Filosofia do Direito.

20 Idem, p. 163-166. Conferir, por exemplo, o site: <http://www.verfassungen.de/de/de06-66/karlsbad19. $\mathrm{htm}>$.

21 SINGER, Peter. Hegel. Tradução de Luciana Pudenzi. São Paulo: Loyola, 2003. p. 59-60. 
Ou seja, urge considerar que Hegel exprimiu sua filosofia política numa época em que a manifestação pública, escrita ou oral, de certas opiniões não era livre e, por isso, em algumas ocasiões, era até pretexto para perseguições e penalidades. Além disso, sabemos que Hegel vivenciou a experiência de censura, em 1808, quando foi editor da Gazeta de Bamberg. Portanto, ele não desfrutou da liberdade para poder declarar toda e qualquer opinião possível. Mas, independente de tal não liberdade, Hegel nunca procurou defender que liberdade de imprensa significava a liberdade para alguém expressar o que bem quisesse. Porém, com isso, não se segue que Hegel e/ou sua filosofia foi subserviente à política da época; antes, pelo contrário, a despeito de não poder se expressar livremente, isso não o impediu de lutar contra a censura, e a favor da liberdade racional, como o atesta a leitura dos seus textos. Ao analisar o texto hegeliano, sobretudo do $\S 319$, compreende-se que Hegel, quando da apresentação do seu conceito de liberdade de imprensa, não busca justificar a realidade estatal existente na Prússia, mas visa promover a efetivação da liberdade.

\subsection{Experiências com a imprensa e opinião pública}

a) Redator-chefe da Gazeta de Bamberg

Hegel, como já afirmamos, trabalhou como diretor da Gazeta de Bamberg, de 1807 a 1808. O jornal era composto de quatro pequenas folhas, de formato in-quarto, e aparecia todos os dias da semana, impresso de manhã e colocado à venda depois do meio-dia. Tal Gazeta fornecia, aos cidadãos de Bamberg e ao distrito de Main, as informações relativas ao Estado bávaro e sobre os acontecimentos europeus. Bamberg era um lugar importante, pois, na época, residiam aí ainda os príncipes do Império.

Hegel, enquanto redator, acrescentava às informações um breve comentário, destinado a orientar o leitor. No momento em que Hegel assumiu as funções de redator, desenrolavam-se os últimos atos da guerra francoprussiana, com o cerco de Dantzig e de Kolberg. Ele tinha sido alertado do que poderia acontecer a um jornalista imprudente nesses tempos de guerra. Por exemplo, o governador francês tinha suspendido a Gazeta de Erlangen e prendera, por oito dias, o diretor Stutzman e o censor, pois ousaram difundir, em suas publicações, conforme acusação, falsas notícias e comentários suscetíveis de perturbar a ordem pública.

Ora, no outono de 1808, o redator da Gazeta atraiu, involuntariamente, a atenção do governo. A causa foi um artigo publicado em 19.08 sobre as posições bávaras, quando se preparava a revolta austríaca. Tal artigo continha certo número de indicações precisas sobre a disposição das tropas. Essas 
informações provinham, literalmente, de uma ordem real, contudo tida como secreta. Hegel elaborou o artigo, a partir da cópia de uma ordem militar que um dos empregados de sua gráfica lhe entregara. Isso não escapou a Munique, a qual, através do Ministério dos Assuntos Estrangeiros, ordenou uma investigação para descobrir a origem do artigo. Hegel relatou o que sabia. $\mathrm{Na}$ segunda metade de dezembro, nova requisição de informações teve lugar a propósito deste artigo. A Gazeta de Bamberg respondeu de novo. Não se sabe bem o que aconteceu depois disso. Mas, em 01.11.1808, um decreto do rei foi promulgado em Munique e dirigido a todos os comissários gerais do distrito, segundo o qual apenas as informações, emanadas de fontes oficiais, poderiam ser publicadas. Quanto às outras notícias, o decreto confiava a responsabilidade de censurá-las às pessoas designadas pelas autoridades provinciais. Desde então, o Ministério tornou-se vigilante e Hegel se ressentia da fragilidade de sua posição. No fim deste mês de novembro, ele assumiu a função de professor de Filosofia em Nürnberg. Isso lhe evitou ter de enfrentar uma situação que se tornou mais difícil. O destino do jornal foi decidido rapidamente. Além do último incidente - aquele que tinha conduzido Munique a intervir - a declaração, de 27.01.1809, sob a responsabilidade dos assuntos franceses em Munique, dizia que tivera, muitas vezes, queixas do mau espírito de certas Gazetas da Bavária, notadamente aquelas de Nürnberg e de Bamberg. Ou seja, depois da saída de Hegel, dois números da Gazeta de Bamberg tinham ainda suscitado a ira de Napoleão. Por isso, a Gazeta de Bamberg foi suspensa em 07.02.1809. Enquanto esses acontecimentos se desenrolavam em Bamberg, Hegel já era, depois de três meses, diretor e professor no liceu real de Nürnberg. Mas, com razão, ele atribuiu a sua própria direção a censura causadora da suspensão que atingiu seu sucessor. ${ }^{22}$

Hegel conhece, portanto, a experiência da censura e da suspensão do jornal onde trabalhara em Bamberg, e, ao mesmo tempo, sabe da importância da imprensa, como meio de formação da opinião pública, não obstante seus problemas, suas garantias e suas ambiguidades. ${ }^{23}$

\section{b) Imprensa e opinião nos Escritos Políticos}

Os Escritos Políticos ${ }^{24}$ de Hegel são: A Constituição da Alemanha (18001802), [publicação póstuma], Atas da Assembléia dos estados do reino de

22 Cf. ROSENZWEIG, Franz. Hegel e o Estado. Paris: PUF, 1991. Título original: Hegel et l'État. p. 219-227.

23 Cf. BAVARESCO, Agemir. A teoria hegeliana da opinião pública. Porto Alegre: L\&PM, 2001. p. 115-117.

24 HEGEL, G. W. F. Escritos Políticos: a Constituição da Alemanha. Atas da Assembléia dos estados do reino de Würtemberg em 1815 e 1816. A respeito da 'Reformbill' inglesa. Traduzido do alemão respectivamente por Michel Jacob, Pierre Quillet e Michel Jacob. Paris: Champ Libre, 1977. 
Würtemberg (1815-1816) e o artigo A propósito da 'Reformbill'inglesa (1830). Os três escritos foram redigidos em datas cruciais da história da Europa. Apresentam uma visão geral do pensamento político de Hegel num período de 30 anos, permitindo compreender como Hegel viveu a atualidade política, na imediatidade dos acontecimentos e sob a pressão da opinião pública.

1) Na Constituição da Alemanha, Hegel faz esta dura constatação: "A Alemanha não é mais um Estado". E, partindo deste olhar, ele vai desenvolver toda sua análise: as instituições políticas alemãs, herdeiras da Idade Média, eram ultrapassadas; o funcionamento da justiça imperial era pesado e ineficaz; não existia mais o exército e nem a polícia para garantir a defesa exterior e a manutenção da ordem interior. Enfim, o direito constitucional havia se convertido em direito privado e não havia poder soberano na Alemanha.

Em seu primeiro projeto de introdução da Constituição, Hegel diz que o poder do universal, enquanto fonte de todo o direito, desapareceu, pois se fragmentou e passou ao estado de particular. Portanto, o universal não existe mais, enquanto realidade, mas somente enquanto pensamento. A opinião pública perdeu a confiança no Estado e decidiu ocupar-se dos negócios particulares. "Não há quase necessidade de propagar uma consciência mais clara do que a opinião pública, perdendo confiança, decidiu mais ou menos obscuramente. Portanto, todos os direitos existentes não têm fundamento, senão nesta relação à totalidade: mas este fundamento, desaparecido depois de muito tempo, tem deixado todos (os direitos) se particularizar". ${ }^{25}$ Por isso, é difícil, para os homens, de maneira geral, fazer a experiência de conhecer e avaliar a necessidade de uma Constituição. "Pois entre os acontecimentos e a livre opinião que é preciso ter, eles introduzem uma multidão de noções e de intenções e quereriam que isso que acontece lhes seja conforme" ${ }^{26} \mathrm{~A}$ liberdade de opinião leva à obrigação de pensar a necessidade ou o que é do interesse de todos e não de ficar fechado nas suas ideias, fazendo de tais ideias, fundadas apenas naquilo que aquela consciência particular pensa, o reino da necessidade. A opinião é livre, quando é capaz de conceber um sistema regido por um espírito que ultrapassa os limites dos acontecimentos particulares. "Sobre a base desta atividade opiniosa, que somente recebe o nome de liberdade, formaram-se sistemas hierárquicos, segundo o azar e o caráter dos homens, sem referência a um interesse geral e sem ser verdadeiramente limitado pelo que se chama poder de Estado; pois esse último era quase inexistente na sua 
oposição aos indivíduos". ${ }^{27}$ No lugar de ser uma opinião livre, segundo Hegel, o que se constituiu na Alemanha foi uma atividade opiniosa, unicamente em direção aos interesses particulares, e o Estado nada fez a não ser constatar que o poder lhe foi tirado.

2) As Atas da Assembléia dos estados do reino de Würtemberg, em 1815 e 1816, expõem o conflito que afeta o rei Frederico II, de Würtemberg, na assembleia dos estados de seu reino, a respeito de um projeto de Constituição que se torna negócio político. Hegel faz a análise, seguindo os trinta e três cadernos das Atas publicadas pela mesma assembleia depois da segunda sessão. O autor demonstra vivo interesse por este assunto provincial. Aqui ele se sente em casa, pois passou sua infância e fez seus estudos secundários em Stuttgart - onde seu pai fora funcionário de finanças do antigo ducado de Würtemberg - e seus estudos universitários em Tübingen. Tal assembleia foi convocada para que aceitasse ou rejeitasse a Carta constitucional, proposta pelo rei. A assembleia beneficiou-se da sustentação de grande parte da opinião pública, seja através da imprensa escrita (entre outros jornais, por exemplo, o Allgemeine Zeitung consagra artigos a seus debates), seja da parte do povo mesmo, que lhe oferece "música de noite" para uma de suas últimas sessões. Mas o rei não era popular, por isso sua Carta foi aceita apenas mais tarde, depois de sua morte — em 25.09.1818 — após o ultimatum. Hegel não se priva de criticar os parlamentares e os acusa de ineficácia, de incapacidade, de cegueira, de venalidade. Ele os censura de alienar o povo, de ser das "classes" (Klassen) dos parasitas, que bloqueiam a situação política em proveito dos interesses da aristocracia burguesa e dos privilégios de casta - "Meu povo, teus chefes te enganam!". ${ }^{28} \mathrm{E}$ eis o paradoxo: o parlamento quer defender seus privilégios e o direito privado, enquanto o rei propõe uma Constituição implicando severas restrições de seus próprios poderes em benefício do povo ou de seus representantes. "Em Würtemberg, é o rei que coloca a Constituição no plano do direito racional e os estados que se lançam na defesa do direito positivo e dos privilégios". ${ }^{29}$

Esse cenário de princípios e de interesses contraditórios da assembleia é "portanto de uma importância infinita para a educação política, da qual um povo e seus chefes têm necessidade, um povo que viveu, até então, na nulidade política e cuja educação não começou do nada, como um povo ainda ingênuo,

27 Ibidem, p. 36.

28 Idem. Atas da Assembléia dos estados de Würtemberg, p. 320. Hegel cita, aqui, o verso do livro do profeta Isaías 3, 12.

29 Ibidem, p. 255-256. 
mas que ainda estava preso nas cadeias severas de uma aristocracia opressiva, de uma Constituição interna organizada para mantê-los, numa carência e numa confusão conceitual completa, a respeito dos direitos políticos e das liberdades, ou antes, nas cadeias das palavras". ${ }^{30}$ Contra isso, Hegel propõe o começo do combate direto e indireto, uma ação sobre o público, pois a educação política se faz pelo debate e pela publicidade dada aos debates da assembleia e, em particular, pela imprensa. Tem-se conhecimento de uma série de artigos que Hegel fez publicar nos Anais Literários de Heidelberg para influenciar a opinião pública.

Hegel começa por observar, nas suas análises políticas, que um dos aspectos importantes para a assembleia é a publicação das Atas e a repercussão observada no público: "Essas Atas não expõem, na verdade, senão um dos aspectos principais desta experiência: os trabalhos, que foram acompanhados publicamente, tiveram lugar na assembléia. Na verdade, o público, sobretudo, tem-se interessado, espontaneamente por esta parte oficial das atas da assembléia, aquela que, em todo caso, tem, primeiramente, por característica, fornecer à história materiais dignos dela". ${ }^{31} \mathrm{E}$ acrescenta que a assembleia deve fazer conhecer, sem rodeio, sua opinião verdadeira, pois "é para este fim que existe uma assembléia de estados, não somente para agir, sem debate, mas ainda para expor ao povo e ao mundo seus debates sobre os interesses do Estado". ${ }^{32}$

O papel representado pela opinião pública, na assembleia de Würtemberg, foi, sem nenhuma dúvida, fortemente sublinhado por Hegel. Tanto em relação à publicação das Atas quanto à assembleia enquanto tal, pois Hegel repete, seguidamente, que isso foi um verdadeiro momento de educação política. O público reagiu à publicação das Atas, inclusive Hegel, inicialmente, publicando seu longo comentário nos Anais Literários de Heidelberg e, também, de um modo geral, toda a imprensa. Isso denota um despertar da opinião do povo, que se torna político, pois quer influenciar nos debates da assembleia, propondo e criticando seus projetos. O público também toma posição, e isso desencadeia os debates no nível da mesma assembleia e no interior da sociedade de Würtemberg. A insistência sobre todo esse processo de discussão pública prova o quanto Hegel valoriza o papel da opinião que se torna crítica e educa a consciência política. 
3) O último texto político, publicado por Hegel, é o artigo $A$ propósito da 'Reformbill' inglesa, que apareceu, em 26.04.1831, no Allgemeine Preussische Staatszeitung. Sabe-se que o rei da Prússia censurou a segunda parte do artigo, pois a julgava muito crítica a respeito da Inglaterra, evitando, desse modo, os problemas de política estrangeira. Hegel foi sempre interessado pela economia, pela política e pela vida social inglesa. Por exemplo, desde 1799, ele comentava os Princípios de economia política, de J. Stewart, e, nos seus cursos de Iena, de 1804-1805, escolhe ainda a Inglaterra, a fim de estudar as estruturas da sociedade burguesa. Em 1831, a motivação de Hegel é a vaga revolucionária que, na época, sacudiu a Europa depois de 1830 - Itália, Polônia, França, Bélgica. Nos dois primeiros países, a revolta fracassou; ao contrário, nos últimos, ela foi vitoriosa e na Inglaterra a oposição ganhou as eleições. Em 03.1831, o novo gabinete apresentou projeto de reforma eleitoral. A Inglaterra foi agitada por muitos anos pela questão da mudança de sistema eleitoral desusado e injusto. Tal é o objeto da Reformbill. Em 1830, a vida pública inglesa é ainda dominada por tradições muito antigas; em princípio, o rei, hereditário e inviolável, comanda o reino; o governo central compreende duas câmaras - a câmara dos Lords ou a câmara alta, composta de senhores hereditários, e a câmara dos Comuns ou câmara baixa, composta de deputados eleitos pelo tempo de sete anos. O sistema eleitoral inglês é costumeiro e quase medieval. É por isso que o país sente a necessidade de uma reforma eleitoral, que vai ser adotada definitivamente em 05.1832.

$\mathrm{O}$ artigo de Hegel toma posição em relação a esse projeto de reforma eleitoral. Segundo Hegel, a opinião pública já havia tomado partido em favor da reforma. Mesmo assim, ele examina o que a opinião sustentava, pois ela é contraditória: "Entretanto, mesmo se a opinião pública, na Inglaterra, era quase universalmente favorável à reforma prevista pelo Bill, quaisquer que sejam a extensão ou os limites, deveria ser ainda permitido examinar o que esta opinião exige". 33

Ao projeto faltavam fundamento sólido e argumentos verdadeiros. Ao contrário da Alemanha, onde a opinião pública se formou conforme um processo de mudança progressivo, na Inglaterra a opinião tomou posição em favor do projeto de reforma de modo imediato. É isso que Hegel censura na opinião inglesa: o fato de se voltar contra o que ela antes tinha sustentado. De toda maneira, isso corresponde ao próprio conceito da opinião pública, de ser sempre a expressão da contradição das opiniões da sociedade. 
Assim, as análises dos Escritos Políticos demonstram-nos que Hegel está consciente do papel da opinião pública e de seu poder de influenciar os negócios públicos. E, nesse sentido, ele participa desse processo de formação da opinião, através de suas publicações e seus artigos na imprensa escrita. Constata-se que, para Hegel, a opinião tem, sobretudo, um papel político, quer seja no debate parlamentar, quer na formação das ideias no interior da sociedade. Os instrumentos privilegiados de expressão da opinião, na época, são os debates parlamentares e a imprensa: os jornais, as brochuras, os livros, etc. $^{34}$

\subsection{Liberdade de imprensa e opinião pública}

Hegel define a liberdade como o direito de fazer tudo o que as leis permitem. Mas ele não compreende a liberdade da imprensa simplesmente como a liberdade de dizer e de escrever o que se quer. Sustentar isso, diz Hegel, é permanecer no estado do pensamento grosseiro e inculto, da superficialidade da representação, e isso seria regressar em direção à opinião subjetivista. "A essência do Estado moderno consiste na união da universalidade com a total liberdade da particularidade". ${ }^{35}$ A liberdade, que une esses dois elementos, ultrapassa o arbitrário subjetivista e o arbitrário despótico. A liberdade é o pressuposto essencial da comunicação pública em todos os casos. Por exemplo, se a expressão de uma opinião é subjetiva e, às vezes, arbitrária —é sua essência mesma - , a supressão dessa liberdade não deve acontecer em nenhum caso, pois a liberdade subjetiva e sua garantia são um direito objetivo no Estado.

O exercício da palavra e o da imprensa formam a comunicação pública. É o espaço imediato onde se exprime a opinião pública e, ao mesmo tempo, é assim que se forma a opinião. Neste sentido, a comunicação pública é a forma de "satisfação desta viva tendência de dizer e de ter dito sua opinião". O Estado moderno propicia aos seus cidadãos a satisfação deste impulso da opinião, isto é, cada indivíduo sabe que é reconhecido na sua liberdade de opinar, sabe que é membro ativo da comunidade, sabe que é conhecido e reconhecido como tal por todos os outros e pelo Estado na comunicação pública. É por isso que essa liberdade e essa satisfação, enquanto reconhecimento, são o fim da comunicação pública e a razão de sua garantia.

Em princípio, Hegel é partidário da liberdade da comunicação pública. Para que isso se realize, põe duas garantias. A garantia direta se exerce através dos dispositivos legais ou ordens, que podem ser utilizados, antes, como prevenção, 
ou, depois, como punição. Outros veem, nas disposições legais ou ordens, uma censura prévia, embora Hegel não utilize esta palavra. Nós sabemos que essa passagem é uma das mais delicadas, pois é aqui que Hegel exige a abolição da censura, à qual seu livro era ainda submetido, para poder dizer livremente - e não somente de um modo técnico - o que tem a dizer, isso que diriam mais tarde, provavelmente, seus alunos. ${ }^{36}$ É verdade que o governo tem razão de intervir logo que a liberdade de expressão ultrapassa certos limites. Mas a supressão pura e simples da imprensa conduz sempre à revolta do cidadão, e isso é contrário à natureza mesma da liberdade de expressão. A garantia direta da comunicação pública deve sempre levar em conta o fato de que a expressão livre da opinião é, em si, um direito objetivo no Estado.

As garantias indiretas são como uma espécie de autorregulação da comunicação livre, fundada sobre a sabedoria da Constituição, a estabilidade do governo e a publicidade dos debates das assembleias dos estados. Hegel diz, mais uma vez, que a publicidade dos debates das assembleias, quando são levados com competência - logo que se trata de um verdadeiro debate sobre os interesses do Estado - , deixa poucas coisas de importância a acrescentar. Os debates das assembleias esclarecem a opinião pública, exprimem todas as potencialidades e seus interesses sobre os assuntos públicos. O bom senso da opinião pública - vox populi, vox Dei - faz parte das garantias indiretas, pois esse bom senso sabe discernir sabiamente a verdadeira comunicação pública da falsa, de tal modo que esta aqui é recebida com indiferença e desprezo, quando o discurso ou a conversa é fraco ou detestável.

Hegel constata o fenômeno da ambiguidade na comunicação pública: "Aliás, é da natureza mesma da coisa que, em nenhuma parte, o formalismo se mantém com tanta obstinação e de modo assim tão insensato quanto nesta matéria. Pois o objeto - a imprensa — é constituído pelo que aí tem de mais passageiro, de mais particular, de mais contingente na opinião, com a infinita diversidade do conteúdo e dos modos de o exprimir". ${ }^{37}$ A ambiguidade da comunicação pública reside no formalismo e no conteúdo da opinião, pois eles são indeterminados. A arte e a sutilidade na expressão

36 Cf. FLEISCHMANN, Eugène. A filosofia política de Hegel: (la philosophie politique de Hegel: sous forme d'un commentaire des fondements de la philosophie du droit). Paris: Gallimard, 1992. p. 334; D'HONDT, J. Teoria e prática políticas em Hegel: o problema da censura. In: HENRICH, D.; HORSTMANN, R.-P (Ed.). Hegels Philosophie des Rechts. Stuttgart: Klett-Cotta, 1982. p. 151-184. Segundo J.-F. Kervégan, a discussão sobre esse ponto foi reanimada por K. H. Ilting, para quem Hegel teria na sua obra de 1820 disfarçado por medo da censura a orientação liberal natural de seu pensamento, que se manifestaria bem mais livremente nos seus cursos, in Hegel, Carl Schimitt: o político entre especulação e positividade. Paris: PUF, 1992. p. 277.

$37 \mathrm{FD}, \S 319 \mathrm{~A}$. 
são gerais e indeterminadas nelas mesmas. Esta indeterminação inclui uma forma dissimulada e ela está ligada a consequências imprevisíveis, pois a opinião é ignorada se resulta em qualquer coisa distinta do que foi realmente expresso. Ora, "o caráter indeterminado do conteúdo e da forma impede as leis de atingirem, nesse domínio, esta precisão que se exige de uma lei e faz do julgamento pronunciado uma decisão inteiramente subjetiva, pois o delito, a injustiça, o dano causado tomam aqui uma figura particularmente subjetiva". ${ }^{38} \mathrm{O}$ dano atinge o pensamento, a opinião, a vontade de outro como uma realidade efetiva. Como a liberdade dos outros é atingida, é a estes que cabe decidir se a expressão ofensiva do pensamento é realmente um ato e não uma simples opinião.

Outra ambiguidade vem do que se extrai do argumento da simples subjetividade do conteúdo e da forma da opinião. A lei é ambígua, sua imprecisão permite estilos e formulações particulares do pensamento, que desnaturam a lei ou fazem passar as decisões da justiça para os julgamentos puramente subjetivos. Quando a expressão é considerada como causa de dano, é sempre possível sustentar que não se trata de um ato, mas somente de uma opinião, de um pensamento ou, ainda, de um modo de dizer. A argumentação que se funda sobre a subjetividade do conteúdo e da forma da opinião pode exigir, de uma parte, a impunidade para essas palavras ou esses pensamentos, pois se diz que eles são insignificantes e sem importância, pois não são mais que uma simples opinião. De outra parte, a argumentação subjetivista pode exigir o respeito de toda opinião pessoal, pois ela é uma propriedade espiritual e, enquanto tal, a expressão e o uso do direito de propriedade.

A comunicação pública comporta o elemento subjetivo que, dado o caráter indeterminado de suas atividades, possui, na sua expressão, um caráter substancial, mas que age sobre o terreno subjetivo. "O caráter indeterminado das atividades, que resulta das modalidades de sua expressão, não suprime seu caráter substancial e não tem por conseqüência senão o terreno subjetivo sobre o qual elas têm sido completadas [e] determina, igualmente, a natureza da reação". ${ }^{39}$ As ofensas feitas à honra dos indivíduos, a calúnia, a difamação, a falta de consideração a respeito do governo, da autoridade de seus funcionários e, em particular, a respeito do príncipe, o fato de transformar as leis em ridicularização ou incitar à revolta são, para Hegel, todos exemplos de crimes ou delitos da comunicação pública, que mostram seu elemento substancial. Como o caráter substancial da comunicação da opinião não tem 
por consequência a não ser o terreno subjetivo - é esse o terreno subjetivo sobre o qual se coloca o delito que ocasiona o seu aspecto subjetivo, sua contingência -, ele determina, igualmente, a natureza da reação. Pode ser sancionado - o aspecto subjetivo — por uma simples medida de polícia, destinada a impedir o delito ou por uma pena propriamente dita. De toda maneira, permanece sempre o formalismo, que faz parte da comunicação pública. A fronteira entre o elemento subjetivo e o elemento substancial - o delito objetivo - é sempre fluida, por causa do caráter subjetivo dos delitos de opinião. Não se chega a qualificá-los objetivamente, e toda condenação guarda um caráter de apreciação subjetiva.

Nas ciências autênticas não há ambiguidades, pois elas não se situam sobre o terreno das opiniões subjetivas ou na categoria que constitui a opinião pública. "As ciências, ao contrário, quando são verdadeiras, não se situam sobre o terreno das opiniões e do ponto de vista subjetivo. É por isso que não entram na categoria do que constitui a opinião pública". ${ }^{40}$ Não se pode limitar a liberdade das ciências, contrariamente àquela da imprensa e da opinião pública; elas não podem mais ser submetidas ao controle do governo ou a qualquer disposição jurídica, pois não estão sobre o mesmo plano que as opiniões subjetivas e seu modo de exposição não consiste na arte de torneamentos verbais, de alusões, de subentendidos (meias-palavras ou encobrimentos), mas numa expressão sem equívoco, precisa e clara de seu conteúdo, com significado e sentido determinado, exato e evidente.

Porém, a imprensa pode comportar a injustiça. Segundo Hegel, a expressão injusta pode ser permitida ou tolerada, em razão do desprezo em que ela cai; e a parte da expressão injusta, que fica sob a ação da lei, pode ser imputada a esta sorte de Nêmesis - uma das divindades primordiais gregas, personificando a indignação, a vingança dos deuses contra o excesso.

Hegel conclui esta análise da liberdade da comunicação pública, seja pela imprensa, seja pela palavra, seja pela ciência, dizendo que seus efeitos próprios e os perigos que eles apresentam para os indivíduos, a sociedade e o Estado dependem da natureza do terreno. Mas o que ele entende pela expressão "natureza do terreno"? Ele mesmo faz referência ao § 218, da Filosofia do Direito, para dar o sentido. No parágrafo, Hegel trata do problema do crime e de seus efeitos sobre a sociedade civil-burguesa. Conclui que, na medida em que o poder da sociedade se tornou seguro, a importância exterior da violação diminui e isso conduz à maior clemência exterior quanto à pena. É impossível 
à sociedade deixar o crime impune, pois isso seria então posto como direito, mas, como a sociedade se torna mais e mais segura de si mesma, o crime torna-se mais e mais, em relação a ela, qualquer coisa de singular, de isolado e de instável. Enfim, diz que um Código Penal é relativo essencialmente ao seu tempo e ao estado correspondente da sociedade civil. Do mesmo modo, os efeitos próprios e os perigos que a comunicação pública apresenta para os indivíduos, a sociedade e o Estado dependem da "natureza do terreno", isto é, do poder da sociedade, da sua evolução. Assim, Hegel conclui que as disposições acerca dos crimes e de suas respectivas punições dependem de cada nação e de seu estágio na busca da ideia de liberdade. Do mesmo modo, em relação à opinião pública e às suas externações e respectivas punições, tudo depende da "natureza do terreno", da natureza da sociedade civil, de seu desenvolvimento e de sua capacidade de debater publicamente. ${ }^{41}$

\section{Liberdade de imprensa e opinião: a força da contradição}

Partimos do pressuposto hegeliano de que a opinião pública é uma contradição que necessita passar por várias mediações, a fim de instaurar cenários de uma democracia que garante a liberdade de imprensa cidadã. A opinião caracteriza-se pela impaciência, querendo, imediatamente, a realização da vontade da pessoa. A opinião não suporta a lentidão da paciência das mediações do conceito e o longo processo de efetivação de suas determinações históricas. Isso porque a opinião exerce papel capital no cenário sociopolítico, enquanto ela contém em si a força da contradição e a reserva da indignação moral e ética, que faz mudar toda situação que não corresponde à ideia de liberdade. Em nível do "direito abstrato", a impaciência da opinião busca realizar seu direito privado e defender seus interesses particulares, porém, em nível da liberdade pública, a impaciência do opinar torna-se portadora dos interesses universais.

Os cenários da liberdade de imprensa e da opinião pública, apresentados ao longo do estudo, descrevem esta dialética entre a impaciência da opinião e a paciência da mediação. Na breve história da formação da liberdade de imprensa, constata-se que, à medida que crescem as mudanças técnicas da comunicação, também se estabelece a regulamentação da imprensa. De fato, o fenômeno da constituição da liberdade de imprensa acontece ao mesmo tempo que se constitui a formação da opinião pública enquanto contradição. $\mathrm{O}$ fenômeno da opinião pública é contraditório, porque contém em si, ao mesmo 
tempo, a universalidade dos princípios constitucionais, do Direito e da Ética, junto com a singularidade dos direitos e interesses dos cidadãos e da expressão de sua subjetividade. Ora, esta contradição encontra a sua solução através da mediação da liberdade da própria imprensa dentro de um quadro de legalidade democrática. Esta é a força da contradição: Efetivar a mediação da tensão dialética entre os polos opostos do universal e do singular na liberdade da imprensa, garantindo o direito de todo cidadão expressar publicamente a sua opinião. Esta é teoria da opinião pública hegeliana: a liberdade de imprensa e o parlamento, enquanto espaço político, são esferas privilegiadas da mediação do fenômeno contraditório da opinião pública.

O cenário da sociedade atual caracteriza-se pela cultura de massas e pela cultura do espetáculo, em que todos querem ser protagonistas, mostrar o que sabem fazer e expressar a sua opinião. Temos o MySpace, o YouTube, os blogs, lista de e-mails e sites independentes, etc. Todos querem se expressar, todos são atores e/ou espectadores e querem participar da sociedade. Isto pressupõe a liberdade de imprensa e a opinião pública enquanto fenômeno contraditório. Por isso, retorna o problema: Partindo do pressuposto da liberdade de imprensa, como garantir que a sociedade resolva a contradição da opinião pública?

Aresposta a este problema dá-se, primeiramente, por aqueles que defendem a necessidade de uma Lei de Imprensa, argumentando o seguinte: a) É preciso restaurar a hierarquia constitucional: juízes não podem praticar atos de censura prévia, ainda que seja no intuito de defender os valores da personalidade; b) Sem Lei de Imprensa, só grandes empresas têm boas condições de proteger-se da má aplicação da lei comum, levando processos até as mais altas instâncias do Judiciário. Enquanto os veículos menores e as iniciativas individuais são mais expostos ao jogo bruto do poder e às decisões abusivas de magistrados; c) Garantir o devido amparo legal à efervescente "imprensa cidadã", que dissemina blogs pela internet - inovações que merecem ter proteção especial da Lei de Imprensa quando revestirem caráter jornalístico; d) $\mathrm{O}$ interesse público de conhecer a verdade, de ter acesso à diversidade de opiniões e de questionar o poder precisa da proteção de nova Lei de Imprensa. ${ }^{42}$

Em segundo lugar, os que defendem a ausência absoluta de Lei de Imprensa inspiram-se no direito anglo-americano que não editou lei reguladora da imprensa, porque a tradição daqueles povos supre, pelos costumes e pelas aplicações extensivas, a ausência de marcos regulatórios específicos. A 
partir dessa tradição, afirmam que não há necessidade de lei especial para regulamentar a liberdade de imprensa.

Diante desta oposição de posições, sabe-se que o fenômeno da contradição da opinião pública necessita da liberdade de imprensa, incluindo os novos cenários da comunicação, sabendo-se que tanto a legislação ou a ausência dela implica espaços de mediação, enquanto garantia de validade e legitimidade das democracias das sociedades ocidentais.

\section{Referências}

ALVES, A. Imprensa. In: Polis: enciclopédia verbo da sociedade e do Estado. Lisboa: São Paulo: Verbo, 1985.

BAVARESCO, Agemir. A teoria hegeliana da opinião pública. Porto Alegre: L\&PM, 2001.

D'HONDT, J. Teoria e prática políticas em Hegel: o problema da censura. In: HENRICH, D.; HORSTMANN, R.-P (Ed.). Hegels Philosophie des Rechts. Stuttgart: Klett-Cotta, 1982. p. 151-184.

FLEISCHMANN, Eugène. A filosofia política de Hegel: (la philosophie politique de Hegel: sous forme d'un commentaire des fondements de la philosophie du droit). Paris: Gallimard, 1992.

GOMES, Pedro Gilberto. Comunicação social: filosofia, ética, política. São Leopoldo: UNISINOS, 1997.

HEGEL, G. W. F. Enciclopédia das ciências filosóficas em compêndio (1830): I - A ciência da lógica. Tradução de Paulo Meneses. São Paulo: Loyola, 1995.

HEGEL, G. W. F. Escritos Políticos: a Constituição da Alemanha. Atas da Assembléia dos estados do reino de Würtemberg em 1815 e 1816. A respeito da 'Reformbill' inglesa. Traduzido do alemão respectivamente por Michel Jacob, Pierre Quillet e Michel Jacob. Paris: Champ Libre, 1977.

HEGEL, G. W. F. Linhas fundamentais da filosofia do direito ou direito natural e ciência do estado em compêndio: Terceira parte: a Eticidade; Terceira seção: o Estado. Tradução de Marcos Lutz Müller. Campinas: IFCH/UNICAMP, 1998. (Textos Didáticos; n. 32).

KERVÉGAN. J.-F. Hegel, Carl Schimitt: o político entre especulação e positividade. Paris: PUF, 1992.

KONZEN, Paulo Roberto. O conceito de Estado e o de liberdade de imprensa na filosofia do direito de G. W. F. Hegel. Dissertação (Mestrado em Filosofia) Universidade Federal do Rio Grande do Sul, Porto Alegre, 2007.

ROSENZWEIG, Franz. Hegel e o Estado. Paris: PUF, 1991. Título original: Hegel et l'État.

SINGER, Peter. Hegel. Tradução de Luciana Pudenzi. São Paulo: Loyola, 2003. 